Published in final edited form as:

Cell Mol Life Sci. 2006 May ; 63(10): 1165-1178.

\title{
Lipid-lowering drugs
}

\author{
K. Pahan \\ Section of Neuroscience, Department of Oral Biology, University of Nebraska Medical Center, 40th \\ and Holdrege, Lincoln, Nebraska 68583 (USA)
}

\begin{abstract}
Although a change in life-style is often the method of first choice for lipid lowering, lipid-lowering drugs, in general, help to control elevated levels of different forms of lipids in patients with hyperlipidemia. While one group of drugs, statins, lowers cholesterol, the other group, fibrates, is known to take care of fatty acids and triglycerides. In addition, other drugs, such as ezetimibe, colesevelam, torcetrapib, avasimibe, implitapide, and niacin are also being considered to manage hyperlipidemia. As lipids are very critical for cardiovascular diseases, these drugs reduce fatal and nonfatal cardiovascular abnormalities in the general population. However, a number of recent studies indicate that apart from their lipid-lowering activities, statins and fibrates exhibit multiple functions to modulate intracellular signaling pathways, inhibit inflammation, suppress the production of reactive oxygen species, and modulate $\mathrm{T}$ cell activity. Therefore, nowadays, these drugs are being considered as possible therapeutics for several forms of human disorders including cancer, autoimmunity, inflammation, and neurodegeneration. Here I discuss these applications in the light of newly discovered modes of action of these drugs.
\end{abstract}

\section{Keywords}

Fibrate; statin; pleiotropic function; signal transduction; human disorder

\section{Introduction}

Lipids are important biomolecules. Cholesterol, for example, is an essential component of the human cell membrane and a precursor for steroid hormones and bile acids. Triglycerides also play an important role in transferring energy from food into body cells. However, any biomolecule in excess is not good for human health. Similarly, elevation of different forms of lipids in the bloodstream, a condition generally termed hyperlipidemia, causes a constant health problem. Because lipids are carried in the bloodstream, hyperlipidemia is always a threat to coronary arteries and the most important risk factor for coronary heart disease.

However, to fight these problems, human wit has acquired several drugs, commonly known as lipid-lowering drugs. One group of drugs (statins) lowers cholesterol by interfering with the cholesterol biosynthetic pathway $[1,2]$. On the other hand, fibrates decrease fatty acid and triglyceride levels by stimulating the peroxisomal $\beta$-oxidation pathway [3,4]. Apart from these drugs, ezetimibe, which selectively inhibits intestinal cholesterol absorption [5],

cholestyramine, colestipol, and colesevelam, which sequester bile acids [6], torcetrapib, which inhibits cholesterol ester transfer protein [7], avasimibe, which inhibits acyl-CoA: cholesterol acyltransferase [8], implitapide, which inhibits microsomal triglyceride transfer protein [9], and niacin, which modifies lipoproteins [5], are providing clinicians with several therapeutic options for lipid lowering. However, based on medical use, importance, and popularity, statins

Fax: +1 402472 2551, email: kpahan@unmc.edu 
and fibrates are way ahead of the others. Recent experimental data have revealed that both statins and fibrates display a broad spectrum of activities in addition to their lipid-lowering properties. As a result, statins and fibrates are now being considered as possible medicines in a variety of human disorders.

\section{Lipid-lowering drugs}

Most of the lipid-lowering drugs are classified mainly into two groups - statins and fibrates.

\section{Statins}

The statins inhibit 3-hydroxy-3-methylglutaryl coenzyme A (HMG-CoA) reductase and, thereby, suppress cholesterol biosynthesis (Fig. 1). In the 1970s, Dr. Endo and colleagues in Japan $[10,11]$ were studying how certain fungi protected themselves against others. As ergosterol, a derivative of cholesterol, is an essential component of fungi membrane, they were prompted to investigate if inhibition of cholesterol biosynthesis was one such mechanism. In 1978, they reported the discovery of mevastatin, the first statin drug. Eventually, through the laboratory of Drs. Goldstein and Brown [12,13], these drugs emerged as the most effective means of reducing elevated levels of plasma cholesterol. There are currently seven statins available in pharmaceutical form - lovastatin, simvastatin, pravastatin, fluvastatin, atorvastatin, rosuvastatin, and pitavastatin [6,14]. First-generation statins, such as lovastatin and mevastatin, were isolated from fungi. However, second- and third-generation statins have been developed by either modification of first-generation statins or chemical synthesis in the laboratory. In general, statins share similar chemical characteristics, with second- and thirdgeneration statins having several aromatic rings and an aliphatic fatty acid side chain, and first generation statins having a decalin ring and an aliphatic side chain.

\section{Fibrates}

In contrast to statins, this group of drugs does not inhibit cholesterol biosynthesis. However, these drugs stimulate $\beta$-oxidation of fatty acids mainly in peroxisomes and partly in mitochondria $[3,4,15,16]$. Therefore, this group of drugs is known to lower plasma levels of fatty acid and triacylglycerol. Clofibrate was the first such drug, developed in Japan in the 1960s [17]. Eventually, the discovery of several other fibrate drugs such as ciprofibrate, bezafibrate, fenofibrate, and gemfibrozil has revolutionized lipid-lowering research. However, the enthusiasm has been short-lived, because prolonged use of some of these drugs like clofibrate and ciprofibrate causes peroxisome proliferation leading to hepatomegaly and tumor formation in the liver of rodents [18-22]. Therefore, there are concerns about widespread use of these drugs in humans. Only gemfibrozil and fenofibrate, due to their milder effect on peroxisome proliferation, are being used as lipid-lowering drugs in humans.

\section{Mode of action of statins}

\section{Inhibition of cholesterol biosynthetic pathway}

Statins came into the limelight due to their inhibitory effect on cholesterol biosynthesis. In humans, cholesterol is synthesized from acetyl-CoA via multiple reactions. HMG-CoA reductase is the key rate-limiting enzyme of this biosynthetic pathway (Fig. 1). Statins are structural analogues of HMG-CoA and thereby inhibit HMG-CoA reductase competitively with an affinity about 1000-10,000 times greater than that of the natural substrate. In addition to direct inhibition of cholesterol synthesis, statins have also been shown to lower plasma cholesterol levels indirectly due to up-regulation of the low-density lipoprotein (LDL) receptor [23]. 


\section{Inhibition of small G protein activation}

The activity of several proteins involved in intracellular signaling cascades is dependent on post-translational modification by isoprenylation. As described in Figure 1, isoprenoids such as farnesyl pyrophosphate and geranylgeranyl pyrophosphate are intermediates in the cholesterol biosynthetic pathway. These intermediates serve as important lipid attachment molecules for the $\gamma$ subunit of heterotrimeric G proteins and small G proteins, such as Ras, Rho, and Rac [24,25]. Inactive GDP-bound Ras, Rho, and Rac are localized in the cytoplasm. After isoprenylation, these small $\mathrm{G}$ proteins are translocated to the membrane and converted to active GTP-bound forms [24,25]. Subsequently, activated Ras, Rho, and Rac modulate functions of multiple downstream signaling molecules. Because mevalonate is a precursor of isoprenoids, statins inhibit the synthesis of isoprenoids and thereby suppress the activation of small $\mathrm{G}$ proteins.

\section{Suppression of proinflammatory molecules}

The idea of investigating the role of the mevalonate pathway in the regulation of inducible nitric oxide (NO) synthase (iNOS) and proinflammatory cytokines came from the fact that intermediates of this biochemical pathway are isoprenoids, which are known to play an important role in activating small $\mathrm{G}$ proteins like Ras and Rac as described above. Interestingly, Pahan et al. [26] have shown that lovastatin inhibits the activation of NF- $\kappa \mathrm{B}$ and the expression of iNOS and proinflammatory cytokines [tumor necrosis factor- $\alpha$ (TNF- $\alpha$ ), interleukin (IL)-1 $\beta$, and IL-6] in lipopolysaccharide (LPS)-stimulated rat primary astrocytes. In fact, this landmark finding has revolutionized statin research. Nowadays, statin drugs are being widely considered as potential therapeutic agents against various neuroinflammatory and neurodegenerative disorders. Because lovastatin inhibits HMG-CoA reductase, both mevalonate and farnesyl pyrophosphate (FPP) are capable of reversing the inhibitory effect of lovastatin on the expression of iNOS and the activation of NF- $\kappa$ B [26]. However, addition of ubiquinone and cholesterol to astrocytes does not prevent the inhibitory effect of lovastatin. These results suggest that depletion of FPP, rather than end products of the mevalonate pathway, is responsible for the observed inhibitory effect of lovastatin on the expression of iNOS.

Suppression of LPS-induced activation of NF- $\kappa$ B and expression of iNOS in glial cells by farnesyltransferase inhibitors $[27,28]$ suggests an important role for the farnesylation reaction in the regulation of the iNOS gene. Consistent with a role of farnesylation in the activation of $\mathrm{p} 21^{\text {Ras }}$, a dominant-negative mutant of $\mathrm{p} 21^{\text {Ras }}(\mathrm{S} 17 \mathrm{~N})$ also attenuated activation of NF- $\kappa \mathrm{B}$ and expression of iNOS in rat and human primary astrocytes [27]. Statins also block interferon (IFN)- $\gamma$-inducible [29] and constitutive [30] transcription of the major histocompatibility complex (MHC) class II transactivator (CIITA), which regulates nearly all MHC class II gene expression. Recently, Cordle and Landreth [31] have also indicated that statins inhibit fibrillar $\mathrm{A} \beta$-induced expression of iNOS in mouse BV-2 microglial cells by inhibiting isoprenylation of Rac. Taken together, these studies suggest that mevalonate metabolites regulate the expression of iNOS in glial cells via modulating isoprenylation of small G proteins.

\section{Stimulation of endothelial NOS}

In patients with atherosclerosis and hypercholesterolemia, endothelial function is known to be impaired due to decreased synthesis of endothelium-derived NO [32]. In vascular walls, NO is synthesized from endothelial nitric oxide synthase (eNOS). Although statins inhibit the expression of iNOS, these drugs have been found to stimulate eNOS-derived NO production [33]. This beneficial effect of statins is found to be independent of cholesterol lowering [33]. Reversal of this effect by geranylgeranyl pyrophosphate but not FPP suggests that Rac/Rho but not Ras play a role in down-regulation of eNOS. In addition, Akt has been shown to phosphorylate eNOS and increase the production of NO [34]. On the other hand, mevalonate, 
an intermediate of the cholesterol biosynthetic pathway, inhibits phosphatidylinositol-3 (PI-3) kinase and thereby attenuates the activation of protein kinase B (Akt) [35]. These studies suggest that statins may also favor the up-regulation of eNOS by inhibiting the synthesis of mevalonate and thereby activating the PI-3 kinase-Akt pathway. Furthermore, according to Feron et al. [36], atorvastatin increases NO production by decreasing the expression of caveolin-1, a negative regulator of eNOS.

\section{Inhibition of migration and proliferation of smooth muscle cells}

Migration and proliferation of smooth muscle cells (SMCs) play an important role in the pathogenesis of atherosclerosis [37]. Small G proteins, such as Ras and Rho, are known to promote SMC migration and proliferation. While Ras promotes cell cycle progression via activation of the MAP kinase pathway [38], Rho/Rho kinase induces cell proliferation via destabilization of the inhibitor of cyclin-dependent kinase, p2 $7^{\mathrm{kip} 1}$ [39]. Because statins are capable of inhibiting the activation of Ras and Rho, these drugs also suppress SMC migration and proliferation.

\section{Inhibition of reactive oxygen species production}

Reactive oxygen species (ROS) play many important roles in intracellular signal transduction. Several inflammatory and degenerative stimuli induce the production of ROS via the activation of NADPH oxidase. NADPH oxidase is a five-subunit protein that generates superoxide from molecular oxygen and is composed of two membrane-bound subunits, gp91phox and p22phox, and at least two cytosolic subunits, p47phox and p67phox. Phosphorylation of p47phox results in translocation of the p47phox-p67phox complex to the membrane, where it interacts via multiple binding sites with gp91phox and p22phox. This complex remains incomplete without the participation of Rac, a small G protein, which is known to associate with p67phox and gp91phox [40,41]. As mentioned above, statins inhibit geranylgeranylation of Rac and thereby attenuate NADPH oxidase-mediated generation of superoxide.

\section{Switching of T-helper cells}

CD4 T helper (Th) cells play an important role in controlling two different arms of immunity - cell-mediated immunity and antibody-mediated immunity. While Th1 cells play an important role in cell-mediated immunity, Th2 cells induce humoral or antibody-mediated immunity $[42,43]$. The polarization of Th0 (naive) cells into functionally distinct subsets (Th1 and Th2) are characterized by the patterns of cytokines they produce, with Th1 cells producing IFN- $\gamma$, and Th2 cells producing IL-4 and IL-10 [42,43]. Sometimes, Th2 cells are able to negatively regulate Th1 cell-mediated responses, thus acting in an anti-inflammatory capacity. In healthy human beings, there is a proper balance between Th1 and Th 2 cells. However, once the balance is lost, it leads to immune-related disorders. It has been suggested that altering the Th1/Th2 balance in vivo toward Th2 function could protect against Th1-type autoimmune disease. Interestingly, statins have been found to favor the polarization toward Th2 [44,45]. In experimental allergic encephalomyelitis (EAE), the animal model of multiple sclerosis (MS), statins induce the differentiation of neuroantigen-primed T cells from the Th1 to Th2 mode $[44,45]$. While activated (tyrosine-phosphorylated) signal transducer and activator of transcription (STAT) 4 has a key role in IL-12-dependent Th1 lineage commitment, activation of STAT6 is required for IL-4-dependent Th2 lineage commitment [44]. Interestingly, atorvastatin treatment suppresses the formation of activated STAT4 but stimulates the activation of STAT6 in T cells from atorvastatin-treated or phosphate-buffered saline-treated mice [44]. 


\section{Destabilization of fibrillar amyloid- $\beta$ peptides}

Fibrillar forms of amyloid- $\beta(\mathrm{A} \beta)$ peptide play an important role in the pathogenesis of Alzheimer's disease (AD). These are 39- to 43-residue peptides released due to proteolytic processing of the transmembrane precursor glycoprotein, amyloid precursor protein (APP). The amyloidogenic pathway requires that APP be sequentially cleaved by $\beta$ - and $\gamma$-secretases. $\beta$-Secretase cleaves APP close to the membrane to produce $\beta$ APPs (secreted), and a $12-\mathrm{kDa}$, $\mathrm{C} 100$ transmembrane stub, subsequently cleaved by $\gamma$-secretase to produce the $\mathrm{A} \beta$ peptide and a cytoplasmic fragment with a very short half life $[46,47]$. On the other hand, $\alpha$-secretase cleaves APP within the $\mathrm{A} \beta$ sequence thus preventing its formation [46,47]. Statin treatment has recently been suggested to decrease amyloidogenic APP processing by reducing cellular cholesterol levels [48]. Recent studies have suggested that treatment with statins or depletion of cholesterol appears to increase $\alpha$-secretase cleavage of APP in cells, whereas $\beta$-secretase cleavage and secreted $\mathrm{A} \beta$ levels are decreased $[48,49]$. In contrast, cholesterol enrichment leads to elevated amyloidogenic processing of APP $[48,49]$. In agreement with this, Sidera et al. [50] have demonstrated that high cellular cholesterol levels decrease the glycosylation of mature oligosaccharides in $\beta$-secretase leading to its inhibition. On the other hand, in the presence of lovastatin, the glycosylation process is stimulated, thereby attenuating the function of $\beta$-secretase [50]. However, lovastatin does not inhibit $\beta$-secretase in vitro.

\section{Mode of action of fibrates}

\section{Activation of nuclear hormone receptors}

One of the hallmarks of functions of fibrate drugs is the activation of peroxisome proliferatoractivated receptor (PPAR). PPARs are a group of three nuclear hormone receptor isoforms, PPAR- $\gamma$, PPAR- $\alpha$, and PPAR- $\delta$, encoded by different genes [51,52]. However, fibrate drugs like clofibrate and fenofibrate have been shown to activate PPAR- $\alpha$ with tenfold selectivity over PPAR- $\gamma$ [52]. Bezafibrate acts as a pan-agonist that shows similar potency on all three PPAR isoforms. WY-14643, the 2-aryl-thioacetic acid analogue of clofibrate, is a potent murine PPAR- $\alpha$ agonist as well as a weak PPAR- $\gamma$ agonist. Although these drugs activate PPARs, direct binding of these drugs with PPARs has not been demonstrated. However, in response to fibrate drugs, PPAR- $\alpha$ heterodimerizes with retinoid X receptor- $\alpha$ (RXR- $\alpha)$, and the resulting heterodimer modulates the transcription of genes containing peroxisome proliferator-responsive elements (PPREs) in their promoter sequence [52,53]. In addition to fibrates, a number of natural ligands, such as polyunsaturated fatty acids (PUFAs), leukotriene B4 (LTB4), 8-S-hydroxy eicosatetraenoic acid (8-S-HETE), and prostaglandin J2 (PGJ2), are also known to activate PPARs [51-53]. In the absence of ligands, all three isoforms of PPAR bind to various transcription co-repressors, such as nuclear receptor co-repressor (NCoR) and silencing mediator for retinoid and thyroid hormone receptor (SMRT), and histone deacetylases (HDACs) in a DNA-independent manner [54,55]. On the other hand, ligandmediated activation of PPARs leads to dissociation of co-repressors and concomitant association with various co-activators, such as steroid receptor co-activator 1 (SRC1) and histone acetylases (CBP/p300). Recent studies have also identified a PPAR- $\alpha$-interacting cofactor (PRIC) complex containing many co-activators, such as PPAR-binding protein (PBP), PPAR-interacting protein (PRIP), PRIP-interacting protein with methyltransferase domain (PIMT), and others [54,55].

\section{Stimulation of fatty acid oxidation}

Fatty acids are $\beta$-oxidized mainly in mitochondria. Only very long chain and long-chain fatty acids are $\beta$-oxidized in peroxisomes [56,57]. After chain shortening in peroxisomes, fatty acids are believed to be transported into mitochondria for complete $\beta$-oxidation. However, fibrate drugs are known to stimulate mainly peroxisomal $\beta$-oxidation $[15,16,18]$. Accordingly, after clofibrate treatment, peroxisomal fatty acid $\beta$-oxidation increases up to 20 -fold in the liver of 
rodents $[15,16,18]$. Hepatocytes isolated from clofibrate-fed rats also oxidize more and esterify less of incoming fatty acids than do normal hepatocytes $[15,16,18]$. This increase in fatty acid oxidation is particularly striking for very long chain fatty acids $\left(>\mathrm{C}_{22: 0}\right)$, as these are particularly $\beta$-oxidized in peroxisomes. This stimulatory effect is mediated by PPAR- $\alpha$, and a PPRE, consisting of an almost perfect direct repeat of the sequence TGACCT spaced by a single base pair, has also been identified in the upstream regulatory sequences of each of the genes involved in peroxisomal $\beta$-oxidation [16,58]. In addition to stimulating $\beta$-oxidation, fibrate drugs are also known to stimulate fatty acid $\omega$-oxidation in the liver, and they prevent or reduce the effects of some inhibitors of fatty acid oxidation, such as 4-pen-tenoate, and decanoyl-carnitine [58,59]. Fibrates also increase the activity of acyl-CoA synthetase and the CoA content of liver while the level of malonyl-CoA, the precursor of de novo fatty acid synthesis, goes down [58,59]. Apart from stimulating fatty acid oxidation-associated molecules, fibrates also increase lipolysis via PPAR- $\alpha$-dependent up-regulation of lipoprotein lipase [60].

\section{Peroxisome proliferation and hepatocarcinogenesis}

Fibrates are also termed peroxisome proliferators, because prolonged administration of fibrates to rodents typically leads to proliferation of peroxisomes and hepatomegaly. Continuous administration of fibrate drugs to rodents for $40-50$ weeks also leads to the formation of hepatic tumor [22,58]. However, the mode of action underlying fibrate-induced hepatocarcinogenesis has not yet been fully delineated. In response to fibrate drugs, PPAR- $\alpha$ is believed to mediate alterations in gene expression that eventually lead to increased cell proliferation, decreased apoptosis and increased signaling for replicative DNA synthesis in the liver [58]. These alterations ultimately enable mutant cell populations to proliferate and become neoplastic [58]. It is also known that a number of proteins required for transition into the $\mathrm{S}$ phase of the cell cycle are increased by fibrates, probably via the involvement of PPAR- $\alpha$ [58]. However, functional PPREs have not been characterized in gene promoters of these regulatory molecules. Fibrate drugs have been suggested to induce oxidative stress, which ultimately contributes to an increase in hepatocyte proliferation and oxidative DNA damage [61]. This hypothesis gains momentum as fibrates induce marked up-regulation of peroxisomal acyl-CoA oxidase, the fatty acid $\beta$-oxidizing enzyme that produces $\mathrm{H}_{2} \mathrm{O}_{2}$, without concomitant increase in the peroxisomal marker catalase, the $\mathrm{H}_{2} \mathrm{O}_{2}$-degrading enzyme [22,58].

\section{Suppression of proinflammatory molecules}

Similar to statins, fibrate drugs also inhibit the production of different proinflammatory molecules. Fibrates repress cytokine-induced IL-6 production in SMCs, iNOS activity in murine macrophages, and VCAM-1 expression in endothelial cells [62,63]. The physiological relevance of these observations is further corroborated by the demonstration that fibrates lower plasma levels of inflammatory cytokines such as IL-6, TNF- $\alpha$, and IFN- $\gamma$ in patients with atherosclerosis [63]. Interestingly, not only fibrate, but also PPAR- $\gamma$ ligands [63] have been reported to inhibit production of inflammatory cytokinesby monocytes/macrophages in vitro.

Fibrate drugs also exhibit an anti-inflammatory effect in brain cells. For example, according to Xu et al. [64], all the fibrate drugs tested (ciprofibrate, fenofibrate, gemfibrozil, and WY-14643) inhibit cytokine-induced production of NO in microglia in a dose-dependent manner. Xu et al. [64] also demonstrated that fibrates inhibit the secretion of the proinflammatory cytokines IL- $1 \beta$, TNF- $\alpha$, IL-6, and IL-12 $\mathrm{p} 40$ and the chemokine MCP- 1 by LPS-stimulated microglia. Although mechanisms behind the anti-inflammatory effect of fibrates are currently unknown, these drugs may limit inflammation in part by inducing the expression of $\mathrm{I} \kappa \mathrm{B} \alpha$, which blocks the activation of NF- $\kappa \mathrm{B}$, a transcription factor critical in the activation of a variety of proinflammatory molecules [65]. 
We have also demonstrated that gemfibrozil and clofibrate inhibit the expression of iNOS and the production of NO in human astrocytes [66]. Although gemfibrozil induces PPREdependent reporter activity in human astrocytes, this drug inhibits the expression of iNOS independent of PPAR- $\alpha$ [66]. Gemfibrozil has been found to markedly inhibit the activation of different proinflammatory transcription factors, such as NF- $\kappa \mathrm{B}, \mathrm{AP}-1$, and $\mathrm{C} / \mathrm{EBP} \beta$, which are required for the transactivation of the human iNOS promoter [66].

\section{Switching of T helper cells}

Being important immunomodulators, fibrates also modify functions of T cells. Fibrates are ligands of PPAR- $\alpha$ and resting T cells express PPAR- $\alpha$. Marx et al. [67] have demonstrated that fibrates alone are sufficient to inhibit IL-2, TNF- $\alpha$, and IFN $-\gamma$ production by activated CD4 $+\mathrm{T}$ cells. Fibrates also induce splenocyte production of IL-4, a cytokine important in the differentiation of Th2 cells that are generally believed to protect against the development of EAE [68]. In addition, WY-14643, the synthetic agonist of PPAR- $\alpha$, has been shown to induce apoptosis of lymphocytes, which may protect against autoimmune diseases by ablating autoreactive lymphocytes [69]. Lovett-Racke et al. [70] have demonstrated that fibrates suppress the differentiation of Th1 cells while promoting the differentiation of neuroantigenprimed T cells toward the Th2 mode. Although underlying mechanisms are poorly understood, a recent study suggests that PPAR- $\alpha$ also plays a physiologic role in regulating T-bet, an inducible transcription factor important in the initiation of cytokine gene transcription, particularly Th1 cytokines [71]. This study demonstrates that PPAR- $\alpha$ present in the cytoplasm of $\mathrm{T}$ cells is able to negatively regulate the transcription of T-bet that favors the production of IFN- $\gamma$ by T cells. This regulation occurred independently of DNA binding, suggesting that there may be several mechanisms by which PPAR- $\alpha$ can influence T cell activation and cytokine production.

\section{Therapeutic efficacy of statins}

The current state of knowledge indicates that statins are not only lipid-lowering drugs. Due to multiple functions, these wonder drugs have emerged as possible medicines for many other chronic disorders including neurodegeneration, inflammation, demyelination, cancer, and diabetes. Below, I have tried to analyze a large body of information regarding possible treatment of several human disorders by statins.

\section{Coronary artery disease}

Data from several epidemiological studies have established statins as the most potent class of medicines for cardiovascular diseases. Being a cholesterol-lowering drug, statins are expected to ameliorate cardiovascular problems. However, in addition to lowering cholesterol, statins seem to ameliorate multiple problems in patients with atherosclerosis. For example, statins lower the levels of acute-phase proteins independent of their effects on cholesterol and thereby retard the deleterious effects of advanced atherosclerotic disease [72,73]. There is increasing evidence that inflammation and the underlying cellular and molecular mechanisms contribute to the progression of atherosclerosis [74]. The vascular inflammatory process seems to promote plaque rupture and atherothrombosis, resulting in clinical complications of atherosclerosis. Schillinger et al. [75] have shown that the association between statin use and survival is markedly influenced by the inflammatory status of the patient, suggesting that a reduction of vascular inflammation or attenuation of the effects of inflammatory activity may be an important mechanism by which statins exhibit improved event-free survival. However, in addition to cholesterol-lowering and anti-inflammatory activities, improved endothelial function and plaque stabilization by statins in patients with atherosclerosis may also involve their anti-thrombotic, anti-proliferative, and anti-oxidative effects. 


\section{Cancer}

The interest in studying the effects of statins on various forms of cancer stems from the facts that Ras is involved in at least $30 \%$ of all forms of cancer and that statins are capable of inhibiting the activation of Ras in various cell types [76]. Statins also inhibit the growth of various cell lines either by induction of cell cycle arrest or apoptosis [76,77]. In addition, lovastatin has been reported to reduce invasiveness of lymphoma cells, human glioma cells, melanoma cells, and NIH-3T3 cells in matrigel [76]. Consistently, statins exhibit anti-tumor effects against melanoma, mammary carcinoma, pancreatic adenocarcinoma, fibrosarcoma, glioma, neuroblastoma, and lymphoma in various animal models, leading to either suppression of tumor progression, and/or inhibition of the metastatic process $[76,78,79]$. Consistently, in an epidemiological analysis, fewer cases of melanoma are observed in the lovastatin-treated group compared with the control group [80]. In pre-clinical studies, statins also potentiate the anti-tumor effects of some cytokines and chemotherapeutics [81]. However, clinical trial results do not display particularly encouraging prospect for statin therapy in cancer. In a phase II study by Kim et al. [82], lovastatin ( $35 \mathrm{mg} / \mathrm{kg}$ body weight) was administered to patients with advanced gastric adenocarcinoma. Although this drug regimen leads to transient side effects, such as myalgia and elevated serum creatine phosphokinase, the anti-tumor effect was not very obvious. In another phase I-II trial of lovastatin by Larner et al. [83] in patients with anaplastic astrocytoma and glioblastoma multiforme, high doses of lovastatin were welltolerated with little anti-tumor activity. In the PROSPER trial, increased incidences for breast and colon cancer were also observed in the pravastatin-treated group [84]. However, before writing off statins from cancer trials, it should be remembered that statins specifically target Ras and, therefore, these drugs may have a better success rate against Ras-dependent cancers.

\section{Diabetes}

Patients with type 2 diabetes have an atherogenic lipid profile, which greatly increases their risk of coronary heart disease (CHD) compared with people without diabetes. An estimated $92 \%$ of individuals with type 2 diabetes, without CHD, have a dyslipidemic profile [85]. Consistently, the Heart Protection Study demonstrated an approximately 25\% relative risk reduction of a first coronary event in patients with type 2 diabetes [86]. In the Lescol Intervention Prevention Study (LIPS), routine use of fluvastatin in patients with type 2 diabetes led to a $47 \%$ reduction in the relative risk of cardiac death [87]. An increased oxidative stress has been suggested to contribute to the accelerated atherosclerosis and other problems in diabetic patients. Accordingly, exposure of cultured aortic endothelial cells and SMCs to a high glucose level significantly increased the oxidative stress compared with a normal glucose level [88]. This increase was completely blocked by treatment with pitavastatin. Subsequently, administration of pitavastatin in streptozotocin-induced diabetic rats attenuated the increased oxidative stress in diabetic rats to control levels [88]. In addition to CHD, peripheral neuropathy is a frequent and major complication of diabetes. Interestingly, rosuvastatin restores nerve vascularity, including vessel size, in type II diabetic mice to the levels of nondiabetic mice by stimulating the expression of neuronal nitric oxide synthase (nNOS) in sciatic nerves [89].

Although the mechanisms are poorly understood, these drugs also reduce the risk of leg ulcers and kidney disease that are common in diabetic patients.

\section{Osteoporosis}

Osteoporosis is the most common form of bone-degenerating malady in humans. Statins are also emerging as wonder drugs for bone disorders, such as osteoporosis. Bone morphogenetic proteins (BMPs) are cytokines that promote differentiation of mesenchymal stem cells into differentiated osteoblasts, and bone formation. Interestingly, statins have been found to stimulate the expression of BMP-2 [90] and this phenomenon might be linked directly to the anabolic effect of statins on bone. In addition, IL-6 plays an important role in the pathogenesis 
of osteoporosis [91]. Because isoprenoid-mediated activation of Ras is involved in the induction of IL-6 [26], statins block IL-6 induction in various cell types by depleting isoprenoids.

The role of statins in bone formation was shown in 1999 and, after that, observations of large groups of patients have pointed to a reduction in the risk of osteoporotic fractures with the use of statins compared to those using other lipid-lowering drugs or to the control group $[92,93]$. Epidemiological analyses also indicate a reduction in the risk of osteoporotic fractures with the use of statins, but whether using these drugs may have a beneficial effect on bone turnover is not yet known. We must therefore wait for larger prospective randomized clinical trials before prescribing these drugs in osteoporotic patients.

\section{Alzheimer's disease}

$\mathrm{AD}$ is a neurodegenerative disorder resulting in progressive neuronal death and memory loss. Neuropathologically, the disease is characterized by neurofibrillary tangles and neuritic plaques composed of aggregates of $\beta$-amyloid (A $\beta$ ) protein, a 40- to 43-amino acid proteolytic fragment derived from the amyloid precursor protein. In the early 1990s, the first hint about possible involvement of cholesterol in AD came from observations of enhanced prevalence of $\mathrm{A} \beta$-containing senile plaques among subjects without dementia with coronary artery disease compared with individuals without dementia and heart disease [94]. Although the underlying mechanism has not been identified, elevated levels of circulating cholesterol have been proposed to increase the risk of AD several fold [95]. Subsequently, the cholesterol-AD nexus comes to the forefront with the direct evidence of increased levels of $\mathrm{A} \beta$ in cholesterol-fed New Zealand White rabbits, the small-animal model of human coronary artery disease [96]. Interestingly, removing cholesterol from the diet of animals previously fed a cholesterolenriched diet leads to significant reduction in brain $\mathrm{A} \beta$ levels, attesting an important role for cholesterol in stimulating the production of $\mathrm{A} \beta$ in vivo in the brain [96]. Epidemiological studies also suggest that prior statin use in treating risk of coronary artery disease may reduce the risk of AD later in life [97,98]. Recently, in a double-blind randomized trial with a 1-year exposure to atorvastatin ( $80 \mathrm{mg} /$ day), Sparks et al. [99] found that atorvastatin reduces circulating cholesterol levels and produces a positive signal on each of the clinical outcome measures (such as the Geriatric Depression Scale, the Alzheimer's Disease Assessment Scale, Clinical Global Impression of Change Scale, and Neuropsychiatric Inventory Scale) compared with placebo. However, results should be substantiated by a large multi-center clinical trial in order to establish statin therapy in $\mathrm{AD}$.

\section{Multiple sclerosis}

MS is the most common human demyelinating disease of the central nervous system (CNS) of unknown etiology. A broad-spectrum inflammatory process in the CNS is believed to play an important role in the loss of myelin and myelin-producing cells. Evidence has emerged that statins have immunomodulatory effects in MS. Recent reports showed that statins prevent and reverse chronic and relapsing EAE, an animal model of MS [44,45]. Several immunomodulatory properties of statins may account for their beneficial clinical effect. Statins decrease the migration of leukocytes into the CNS, inhibit MHC class II and co-stimulatory signals required for activation of proinflammatory $\mathrm{T}$ cells, induce a Th2 phenotype in $\mathrm{T}$ cells, and decrease the expression of inflammatory mediators in the CNS, including NO and TNF$\alpha[44,45,100]$. Greenwood et al. [101] have demonstrated that treatment of brain endothelial cells in vitro with lovastatin inhibits Rho-mediated transendothelial T cell migration.

Consistently, they [101] and others [102] also demonstrate that in acute and relapsing-remitting mouse models of MS, lovastatin treatment inhibits leukocyte migration into the CNS and attenuates the development of both acute and relapsing clinical disease. Furthermore, in vitro experiments with human immune cells have shown an immunomodulatory profile of 
statins comparable to that of IFN- $\beta$. Consistent with this, an open-label clinical trial of simvastatin for MS reveals a significant decrease in the number and volume of new magnetic resonance imaging (MRI) lesions and a favorable safety profile [103]. As the evidence of the benefit of statins in MS is currently insufficient, large controlled clinical trials are needed.

Because statin treatment is being considered as a possible therapy for MS patients, it is worth mentioning that the rationale for statin treatment is MS patients should be justified. First, MS is a disease of the younger generation and, therefore, many MS patients do not experience any cholesterol-related problems before, during or after the time of MS attack. Second, the serum concentration of 24S-hydroxycholesterol reflecting brain cholesterol turnover may be a possible marker for neurodegeneration and demyelination in MS [104]. Consistently, Teunissen et al. [105] have demonstrated serum levels of 24S-hydroxycholesterol and lathosterol are lower in patients with primary progressive and in older relapsing remitting MS. Therefore, long-term use of statins in MS patients may eventually prove to be fatal.

\section{Depression}

A couple of studies demonstrate that long-term use of statin leads to reduced risk of depression in patients with coronary artery disease [106,107]. They have demonstrated that risk of depression was $60 \%$ less in individuals using statins than in hyperlipidemic individuals not using lipid-lowering drugs. Interestingly, the use of non-statin lipid-lowering drugs yields a similar, but weaker effect. Although statins attenuate depression in susceptible patients, the molecular mechanisms associated with this beneficial effect of statin are not known. One could be the up-regulation of constitutive NOS (cNOS)-mediated NO production in brain cells by statins. As NO possesses the anti-depressant activity, statins may therefore suppress depression. Alternatively, another possible explanation could be the 'feel-good' effect of statins through improved quality of life due to decreased incidence of cardiovascular events.

\section{Therapeutic efficacy of fibrates}

Discovery of multiple functions of fibrates has allowed clinicians to consider fibrates as potential therapeutic agents for various pathological states including atherosclerosis, obesity, diabetes, inflammation, and demyelination. Here, I present the current state of knowledge regarding the treatment of several chronic diseases by fibrates.

\section{Coronary heart disease}

Fibrates were introduced for treatment of hyperlipidemia. Trials with fibrates have shown a reduction in CHD risk through modification of atherogenic dyslipidemia. The benefit is believed to be due to an increased clearance of very low density lipoprotein-cholesterol, a decrease in triglycerides, an increase in plasma high-density lipoprotein (HDL)-cholesterol via decreased exchange of triglyceride and HDL-cholesterol by the cholesterol ester transfer protein (CETP), and a reduction of hepatic cholesterol biosynthesis. Consistently, in several clinical trials, fibrate drugs alone have been found to cause a significant decrease in triglycerides (20-50\%) and an increase in plasma HDL-cholesterol (14-20\%) [108-110]. Although the reduction in low-density lipoprotein (LDL)-cholesterol by fibrates always remains marginal (5-15\%) [108-110], in a study by Winkler et al. [111], fenofibrate lowers atherogenic small dense LDL more effectively than atorvastatin. However, in general, fibrates seem to be particularly effective in patients for whom a disturbance of the triglyceride-HDL axis is the primary lipid disorder.

In addition to lipid-lowering activity, fibrates are also anti-inflammatory. IL-6 has been shown to play an important role in the pathogenesis of atherosclerosis [112]. Biswas et al. [113] reported that IL-6 induces monocyte chemotactic protein- 1 expression in peripheral blood 
mononuclear cells and U937 macrophages. Thus, suppressing the secretion of IL-6, fibrates may indirectly inhibit the production of potent chemokines involved in monocyte recruitment into the subendothelial space, resulting in less foam cell formation.

In some instances, for better overall outcome, fibrates are also administered in combination with statin. According to Chapman [114], a large percentage of CHD patients on statins alone still succumb to the disease. In a randomized, double-blind, placebo-controlled crossover trial with atorvastatin and fenofibrate in patients with combined hyperlipidemia, the combination therapy was found to be safe and had beneficial additive effects on endothelial function [115]. However, combination therapy may sometimes lead to an impairment in drug clearance $[116,117]$, as the clearance of statin drugs from the body requires cytochrome P450-mediated chemical modification. In addition, gemfibrozil is known to inhibit cytochrome p450 [117] and thereby may cause faulty clearance of statins. Therefore, caution must be exercised when prescribing combination therapy for CHD patients.

\section{Obesity}

Obesity itself is a disease and is a serious risk factor for many other chronic complications, such as diabetes, hypertension, dyslipidemia, and cardiovascular diseases. People become obese when the body takes in more calories than it burns off and those extra calories are stored as fat. Due to its direct stimulatory effect on the catabolism of fat, fibrates have been used as primary or adjunct therapy for several years to control obesity. In obese prone (OP) rats, fenofibrate treatment significantly $(\mathrm{p}<0.05$ ) reduces food intake, weight gain, feed efficiency, and adiposity to the levels seen in control obesity-resistant rats [109]. Fenofibrate treatment also increases whole-body fatty acid oxidation, and stimulates the expression of carnitine palmitoyl transferase I, the enzyme involved in the entry of fatty acyl-CoA into mitochondria, in the liver of OP rats [118].

Obesity is often associated with leptin resistance, as evidenced by hyperleptinemia. Leptin is a 16-kDa protein secreted by fat cells that regulates feeding and energy expenditures by acting at sites primarily within the CNS [119]. Obesity in humans and rodents is almost always associated with a resistance to, rather than a deficiency of, leptin [120]. In fact, leptin itself is elevated in obesity. Leptin resistance arises from impaired leptin transport across the bloodbrain barrier (BBB) and defects in leptin receptor signaling. Interestingly, gemfibrozil restores leptin transport across the BBB [121] and in diet-induced obese rats, gemfibrozil significantly reduces the leptin level [122].

\section{Diabetes}

As mentioned above, patients with type 2 diabetes are at particularly high risk of atherosclerotic events. The Diabetes Atherosclerosis Intervention Study [123] and the St. Mary's, Ealing, Northwick Park Diabetes Cardiovascular Disease Prevention study [124] clearly show that fibrates improve cardiovascular outcomes in patients with type 2 diabetes. In addition to lowering cardiovascular risk, fibrates may also improve insulin sensitivity in diabetic patients. Fat metabolism and sugar homeostasis are inherently related. Insulin is recognized for its role in promoting glucose uptake. However, insulin is also capable of regulating the catabolism of triglycerides through its inhibition of hormone-sensitive lipase. On the other hand, lipid abnormalities also have profound effects on glucose homeostasis. For example, according to Schulman [125], abnormal accumulation of triglycerides and fatty acyl-CoA in muscle and liver may result in insulin resistance. In a number of animal models, fibrates have been shown to lower plasma triglycerides, reduce adiposity and improve hepatic and muscle steatosis, thereby improving insulin sensitivity [126,127]. Although fibrate drugs are widely used to treat hypertriglyceridemia in patients, surprisingly, their effects on insulin sensitivity in humans have not been thoroughly examined. Another putative beneficial effect of fibrates in diabetes 
that has not been much appreciated is reduction in inflammation. Subclinical inflammation always plays an important part in the pathogenesis of type 2 diabetes, primarily as a mediator of obesity-induced insulin resistance [128]. In this connection it is worth mentioning that fibrates are also capable of reducing inflammation.

\section{Multiple sclerosis}

A recent study also suggests that fibrate drugs, such as gemfibrozil and fenofibrate, may be considered as possible therapeutics for MS. The EAE animal model is particularly useful in testing new therapeutic intervention in MS. Lovett-Racke and colleagues [70] have demonstrated that these drugs are able to prevent and treat the disease process of EAE in mice. Although underlying mechanisms are poorly understood, anti-inflammatory property, suppression of Th1 activity, and promotion of the Th2 response might be involved in fibratemediated attenuation of the EAE disease process.

\section{Are fibrate drugs safe in humans?}

Fibrate drugs like ciprofibrate, clofibrate, fenofibrate, and gemfibrozil induce the proliferation of peroxisomes in rats and mice. Continuous administration of these drugs to the rodents for $40-50$ weeks also leads to the formation of hepatic tumor $[22,58,129]$. However, induction of hepatic tumor promotion by fibrate drugs has not been demonstrated in humans, other primates or guinea pig $[129,130]$, species which have lost their ability to synthesize ascorbate due to inherent loss of the gulonolactone oxidase gene. Braun et al. [130] have reported that the evolutionary loss of the gulonolactone oxidase gene may contribute to the missing carcinogenic effect of peroxisome proliferators in humans since ascorbate synthesis is accompanied by $\mathrm{H}_{2} \mathrm{O}_{2}$ production, and consequently its induction can be potentially harmful. Furthermore, recent studies have also revealed that humans have considerably lower levels of PPAR- $\alpha$ in liver than rodents, and this difference may, in part, explain the species differences in the carcinogenic response to peroxisome proliferators [129]. Therefore, hepatic tumor formation may not be a concern in humans. However, combination therapy of cerivastatin and gemfibrozil may cause myopathy and rhabdomyolysis [131], suggesting that such a combination therapy should be prescribed cautiously.

\section{Conclusion}

Over the past several years, scientists have achieved significant progress in unraveling newer aspects of lipid-lowering drugs. However, the contribution and importance of any biomedical field should be judged by two parameters: academic and therapeutic. From the academic point of view, it is important to create a bibliography of the regulation of various biological pathways by lipid-lowering drugs that should help in intellectual expansion of this and other fields. For example, one might predict a possible similarity with and/or merger with another subfield that might provide a more coherent approach for better understanding of a biological process. On the other hand, from the therapeutic point of view, one might expect direct application of lipidlowering drugs in several incurable human disorders. For both aspects, there has already been outstanding success. The reason behind this lies partially in the significant increase in the aging population in recent years. As people expect to live longer, they are more likely to acquire lipid-related disorders, and that itself should boost the market for lipid-lowering drugs.

In addition to lipid-related disorders, these drugs are also stretching their arms in the direction of various human disorders including neuroinflammatory and neurodegenerative diseases. However, a number of unresolved issues raise doubts about the widespread use of lipidlowering drugs in neurological disorders. For example, in $\mathrm{AD}$, it is doubtful that cholesterol is to blame for neurodegenerative pathology. Higher neuronal cholesterol has not been shown to increase $\mathrm{A} \beta$ production. It is also not known whether neurons in $\mathrm{AD}$ have more cholesterol 
than control neurons. On the contrary, the brains of AD patients show a specific downregulation of seladin-1, a protein involved in cholesterol synthesis, and low membrane cholesterol was observed in hippocampal membranes of AD patients with the e4/e4 genotype of ApoE [132]. Similarly, many young MS patients do not experience any lipid-related problems.

Therefore, the challenge is to maintain cholesterol or lipid homeostasis in lipid-independent disorders after the use of lipid-lowering drugs, in order to minimize side effects, and that may not be an easy task. Alternatively, specific targeting of the biological molecule/process but not an unrelated one such as lipid/cholesterol may be another option to achieve a better therapeutic outcome under these conditions. For example, inhibitors of farnesyltransferase or geranyl geranyltransferase may be considered for the treatment of cholesterol-independent disorders, as these drugs do not lower the level of cholesterol while performing one of the most important functions of cholesterol-lowering drugs, i.e., inhibition of small $\mathrm{G}$ protein activation. At present, these drugs are on clinical trial to stop the progression of different forms of cancer.

\section{Acknowledgements}

This study was supported by grants from the National Multiple Sclerosis Society (RG3422A1/1), NIH (NS39940 and NS48923) and Michael J. Fox Foundation for Parkinson Research.

\section{References}

1. Krukemyer JJ, Talbert RL. Lovastatin: a new cholesterol-lowering agent. Pharmacotherapy 1987;7:198-210. [PubMed: 3328165]

2. Hebert PR, Gaziano JM, Chan KS, Hennekens CH. Cholesterol lowering with statin drugs, risk of stroke, and total mortality: an overview of randomized trials. JAMA 1997;278:313-321. [PubMed: 9228438]

3. Watts GF, Dimmitt SB. Fibrates, dyslipoproteinaemia and cardiovascular disease. Curr Opin Lipidol 1999;10:561-574. [PubMed: 10680050]

4. Ozasa H, Miyazawa S, Furuta S, Osumi T, Hashimoto T. Induction of peroxisomal beta-oxidation enzymes in primary cultured rat hepatocytes by clofibric acid. J Biochem (Tokyo) 1985;97:12731278. [PubMed: 4030722]

5. Vasudevan AR, Jones PH. Effective use of combination lipid therapy. Curr Cardiol Rep 2005;7:471479. [PubMed: 16256018]

6. Steinmetz KL. Colesevelam hydrochloride. Am J Health Syst Pharm 2002;59:932-939. [PubMed: 12040732]

7. Gauthier A, Lau P, Zha X, Milne R, McPherson R. Cholesteryl ester transfer protein directly mediates selective uptake of high density lipoprotein cholesteryl esters by the liver. Arterioscler Thromb Vasc Biol 2005;25:2177-2184. [PubMed: 16123327]

8. Kharbanda RK, Wallace S, Walton B, Donald A, Cross JM, Deanfield J. Systemic AcylCoA:cholesterol acyltransferase inhibition reduces inflammation and improves vascular function in hypercholesterolemia. Circulation 2005;111:804-807. [PubMed: 15699266]

9. Ueshima K, Akihisa-Umeno H, Nagayoshi A, Takakura S, Matsuo M, Mutoh S. Implitapide, a microsomal triglyceride transfer protein inhibitor, reduces progression of atherosclerosis in apolipoprotein E knockout mice fed a Western-type diet: involvement of the inhibition of postprandial triglyceride elevation. Biol Pharm Bull 2005;28:247-252. [PubMed: 15684478]

10. Endo A, Kuroda M, Tsujita Y. ML-236A, ML-236B, and ML-236C, new inhibitors of cholesterogenesis produced by Penicillium citrinium. J Antibiot (Tokyo) 1976;29:1346-1348. [PubMed: 1010803]

11. Endo A, Tsujita Y, Kuroda M, Tanzawa K. Inhibition of cholesterol synthesis in vitro and in vivo by ML-236A and ML-236B, competitive inhibitors of 3-hydroxy-3-methyl-glutaryl-coenzyme A reductase. Eur J Biochem 1977;77:31-36. [PubMed: 908337] 
12. Brown MS, Goldsteinm JL. Multivalent feedback regulation of HMG CoA reductase, a control mechanism coordinating isoprenoid synthesis and cell growth. J Lipid Res 1980;21:505-517. [PubMed: 6995544]

13. Bilheimer DW, Grundy SM, Brown MS, Goldstein JL. Mevinolin stimulates receptor-mediated clearance of low density lipoprotein from plasma in familial hypercholesterolemia heterozygotes. Trans Assoc Am Phys 1983;96:1-9. [PubMed: 6388097]

14. Asztalos BF, Horvath KV, McNamara JR, Roheim PS, Rubinstein JJ, Schaefer EJ. Comparing the effects of five different statins on the HDL subpopulation profiles of coronary heart disease patients. Atherosclerosis 2002;164:361-369. [PubMed: 12204809]

15. Moody DE, Reddy JK. The hepatic effects of hypolipidemic drugs (clofibrate, nafenopin, tibric acid, and $\mathrm{Wy}-14,643$ ) on hepatic peroxisomes and peroxisome-associated enzymes. Am J Pathol 1978;90:435-450. [PubMed: 623209]

16. Reddy JK, Goel SK, Nemali MR, Carrino JJ, Laffler TG, Reddy MK, et al. Transcription regulation of peroxisomal fatty acyl-CoA oxidase and enoyl-CoA hydratase/3-hydroxyacyl-CoA dehydrogenase in rat liver by peroxisome proliferators. Proc Natl Acad Sci USA 1986;83:1747-1751. [PubMed: 3456610]

17. Ozawa H, Ozawa T. A 50-year history of new drugs in Japan: the developments of antituberculosis drugs and their influences on the epidemiological aspects. Yakushigaku Zasshi 2002;37:84-94. [PubMed: 12412601]

18. Lazarow PB, Shio H, Leroy-Houyet MA. Specificity in the action of hypolipidemic drugs: increase of peroxisomal beta-oxidation largely dissociated from hepatomegaly and peroxisome proliferation in the rat. J Lipid Res 1982;23:317-326. [PubMed: 7077146]

19. Gray TJ, Beamand JA, Lake BG, Foster JR, Gangolli SD. Peroxisome proliferation in cultured rat hepatocytes produced by clofibrate and phthalate ester metabolites. Toxicol Lett 1982;10:273-279. [PubMed: 7080097]

20. Reddy JK, Krishnakantha TP. Hepatic peroxisome proliferation: induction by two novel compounds structurally unrelated to clofibrate. Science 1975;190:787-789. [PubMed: 1198095]

21. Leighton F, Coloma L, Koenig C. Structure, composition, physical properties, and turnover of proliferated peroxisomes: a study of the trophic effects of Su-13437 on rat liver. J Cell Biol 1975;67:281-309. [PubMed: 406]

22. Rao MS, Subbarao V, Reddy JK. Peroxisome proliferator-induced hepatocarcinogenesis: histochemical analysis of ciprofibrate-induced preneoplastic and neoplastic lesions for gammaglutamyl transpeptidase activity. J Natl Cancer Inst 1986;77:951-956. [PubMed: 2876121]

23. Vaziri ND, Liang K. Effects of HMG-CoA reductase inhibition on hepatic expression of key cholesterol-regulatory enzymes and receptors in nephrotic syndrome. Am J Nephrol 2004;24:606613. [PubMed: 15583480]

24. Seabra MC. Membrane association and targeting of prenylated Ras-like GTPases. Cell Signal 1998;10:167-172. [PubMed: 9607139]

25. Maltese WA. Posttranslational modification of proteins by isoprenoids in mammalian cells. FASEB J 1990;4:3319-3328. [PubMed: 2123808]

26. Pahan K, Sheikh FG, Namboodiri AM, Singh I. Lovastatin and phenylacetate inhibit the induction of nitric oxide synthase and cytokines in rat primary astrocytes, microglia, and macrophages. J Clin Invest 1997;100:2671-2679. [PubMed: 9389730]

27. Pahan K, Liu X, McKinney MJ, Wood C, Sheikh FG, Raymond JR. Expression of a dominant-negative mutant of p21(ras) inhibits induction of nitric oxide synthase and activation of nuclear factor-kappaB in primary astrocytes. J Neurochem 2000;74:2288-2295. [PubMed: 10820188]

28. Pahan K, Sheikh FG, Khan M, Namboodiri AM, Singh I. Sphingomyelinase and ceramide stimulate the expression of inducible nitric-oxide synthase in rat primary astrocytes. J Biol Chem 1998;273:2591-2600. [PubMed: 9446561]

29. Crisby M. Modulation of the inflammatory process by statins. Drugs Today 2003;39:137-143. [PubMed: 12698208]

30. Muczynski KA, Ekle DM, Coder DM, Anderson SK. Normal human kidney HLA-DR-expressing renal microvascular endothelial cells: characterization, isolation, and regulation of MHC class II expression. J Am Soc Nephrol 2003;14:1336-1448. [PubMed: 12707403] 
31. Cordle A, Landreth G. 3-Hydroxy-3-methylglutaryl-coenzyme A reductase inhibitors attenuate betaamyloid-induced microglial inflammatory responses. J Neurosci 2005;25:299-307. [PubMed: 15647473]

32. Dimmeler S, Zeiher AM. Nitric oxide - an endothelial cell survival factor. Cell Death Differ 1999;6:964-968. [PubMed: 10556973]

33. Hernandez-Perera O, Perez-Sala D, Navarro-Antolin J, Sanchez-Pascuala R, Hernandez G, Diaz C, et al. Effects of the 3-hydroxy-3-methylglutaryl-CoA reductase inhibitors, atorvastatin and simvastatin, on the expression of endothelin-1 and endothelial nitric oxide synthase in vascular endothelial cells. J Clin Invest 1998;101:2711-2719. [PubMed: 9637705]

34. Fulton D, Gratton JP, McCabe TJ, Fontana J, Fujio Y, Walsh K, et al. Regulation of endotheliumderived nitric oxide production by the protein kinase Akt. Nature 1999;399:597-601. [PubMed: 10376602]

35. Skaletz-Rorowski A, Lutchman M, Kureishi Y, Lefer DJ, Faust JR, Walsh K. HMG-CoA reductase inhibitors promote cholesterol-dependent Akt/PKB translocation to membrane domains in endothelial cells. Cardiovasc Res 2003;57:253-264. [PubMed: 12504836]

36. Feron O, Dessy C, Desager JP, Balligand JL. Hydroxy-methylglutaryl-coenzyme A reductase inhibition promotes endothelial nitric oxide synthase activation through a decrease in caveolin abundance. Circulation 2001;103:113-118. [PubMed: 11136695]

37. Gordon D, Schwartz SM. Replication of arterial smooth muscle cells in hypertension and atherosclerosis. Am J Cardiol 1987;59:44A-48A.

38. Bhunia AK, Han H, Snowden A, Chatterjee S. Redox-regulated signaling by lactosylceramide in the proliferation of human aortic smooth muscle cells. J Biol Chem 1997;272:15642-15649. [PubMed: 9188453]

39. Laufs U, Marra D, Node K, Liao JK. 3-Hydroxy-3-methylglutaryl-CoA reductase inhibitors attenuate vascular smooth muscle proliferation by preventing rho GTPase-induced down-regulation of p27 (Kip1). J Biol Chem 1999;274:21926-21931. [PubMed: 10419514]

40. Bokoch GM, Knaus UG. NADPH oxidases: not just for leukocytes anymore! Trends Biochem Sci 2003;28:502-508. [PubMed: 13678962]

41. Ago T, Nunoi H, Ito T, Sumimoto H. Mechanism for phosphorylation-induced activation of the phagocyte NADPH oxidase protein p47 ${ }^{\text {phox }}$. J Biol Chem 1999;274:33644-33653. [PubMed: 10559253]

42. Mowen KA, Glimcher LH. Signaling pathways in Th2 development. Immunol Rev 2004;202:203222. [PubMed: 15546395]

43. Crane IJ, Forrester JV. Th1 and Th2 lymphocytes in autoimmune disease. Crit Rev Immunol 2005;25:75-102. [PubMed: 15952931]

44. Youssef S, Stuve O, Patarroyo JC, Ruiz PJ, Radosevich JL, Hur EM, et al. The HMG-CoA reductase inhibitor, atorvastatin, promotes a Th2 bias and reverses paralysis in central nervous system autoimmune disease. Nature 2002;420:78-84. [PubMed: 12422218]

45. Aktas O, Waiczies S, Smorodchenko A, Dorr J, Seeger B, Prozorovski T, et al. Treatment of relapsing paralysis in experimental encephalomyelitis by targeting Th1 cells through atorvastatin. J Exp Med 2003;197:725-733. [PubMed: 12629065]

46. Citron M. Beta-secretase inhibition for the treatment of Alzheimer's disease-promise and challenge. Trends Pharmacol Sci 2004;25:92-97. [PubMed: 15102495]

47. Rossner S. New players in old amyloid precursor protein-processing pathways. Int J Dev Neurosci 2004;22:467-474. [PubMed: 15465276]

48. Cole SL, Grudzien A, Manhart IO, Kelly BL, Oakley H, Vassar R. Statins cause intracellular accumulation of amyloid precursor protein, beta-secretase-cleaved fragments, and amyloid betapeptide via an isoprenoid-dependent mechanism. J Biol Chem 2005;280:18755-18770. [PubMed: 15718241]

49. Hoglund K, Syversen S, Lewczuk P, Wallin A, Wiltfang J, Blennow K. Statin treatment and a diseasespecific pattern of beta-amyloid peptides in Alzheimer's disease. Exp Brain Res 2005;164:205-214. [PubMed: 15937702]

50. Sidera C, Parsons R, Austen B. The regulation of beta-secretase by cholesterol and statins in Alzheimer's disease. J Neurol Sci 2005;229-230:269-273. 
51. Kliewer SA, Xu HE, Lambert MH, Willson TM. Peroxisome proliferator-activated receptors: from genes to physiology. Recent Prog Horm Res 2001;56:239-263. [PubMed: 11237216]

52. Willson TM, Wahli W. Peroxisome proliferator-activated receptor agonists. Curr Opin Chem Biol 1997;1:235-241. [PubMed: 9667857]

53. Chu R, Lin Y, Rao MS, Reddy JK. Cooperative formation of higher order peroxisome proliferatoractivated receptor and retinoid $\mathrm{X}$ receptor complexes on the peroxisome proliferator responsive element of the rat hydratase-dehydrogenase gene. J Biol Chem 1995;270:29636-29639. [PubMed: 8530345]

54. Surapureddi S, Yu S, Bu H, Hashimoto T, Yeldandi AV, Kashireddy P, et al. Identification of a transcriptionally active peroxisome proliferator-activated receptor alpha-interacting cofactor complex in rat liver and characterization of PRIC285 as a coactivator. Proc Natl Acad Sci USA 2002;99:11836-11841. [PubMed: 12189208]

55. Misra P, Qi C, Yu S, Shah SH, Cao WQ, Rao MS, et al. Interaction of PIMT with transcriptional coactivators CBP, p300, and PBP differential role in transcriptional regulation. J Biol Chem 2002;277:20011-20019. [PubMed: 11912212]

56. Lazarow PB. The role of peroxisomes in mammalian cellular metabolism. J Inherit Metab Dis 1987;10:11-22. [PubMed: 3119935]

57. Singh I, Moser AE, Goldfischer S, Moser HW. Lignoceric acid is oxidized in the peroxisome: implications for the Zellweger cerebro-hepato-renal syndrome and adrenoleukodystrophy. Proc Natl Acad Sci USA 1984;81:4203-4207. [PubMed: 6588384]

58. Yu S, Rao S, Reddy JK. Peroxisome proliferator-activated receptors, fatty acid oxidation, steatohepatitis and hepatocarcinogenesis. Curr Mol Med 2003;3:561-572. [PubMed: 14527087]

59. Reddy JK, Hashimoto T. Peroxisomal beta-oxidation and peroxisome proliferator-activated receptor alpha: an adaptive metabolic system. Annu Rev Nutr 2001;21:193-230. [PubMed: 11375435]

60. Staels B, Schoonjans K, Fruchart JC, Auwerx J. The effects of fibrates and thiazolidinediones on plasma triglyceride metabolism are mediated by distinct peroxisome proliferator activated receptors (PPARs). Biochimie 1997;79:95-99. [PubMed: 9209702]

61. Yeldandi AV, Rao MS, Reddy JK. Hydrogen peroxide generation in peroxisome proliferator-induced oncogenesis. Mutat Res 2000;448:159-177. [PubMed: 10725470]

62. Delerive P, De Bosscher K, Besnard S, Vanden Berghe W, Peters JM, Gonzalez FJ, et al. Peroxisome proliferator-activated receptor alpha negatively regulates the vascular inflammatory gene response by negative cross-talk with transcription factors NF-kappaB and AP-1. J Biol Chem 1999;274:3204832054. [PubMed: 10542237]

63. Daynes RA, Jones DC. Emerging roles of PPARs in inflammation and immunity. Nat Rev Immunol 2002;2:748-759. [PubMed: 12360213]

64. Xu J, Storer PD, Chavis JA, Racke MK, Drew PD. Agonists for the peroxisome proliferator-activated receptor-alpha and the retinoid $\mathrm{X}$ receptor inhibit inflammatory responses of microglia. J Neurosci Res 2005;81:403-411. [PubMed: 15968640]

65. Delerive P, Gervois P, Fruchart JC, Staels B. Induction of $\mathrm{I} \kappa \mathrm{B} a$ expression as a mechanism contributing to the anti-inflammatory activities of peroxisome proliferator-activated receptor- $\alpha$ activators. J Biol Chem 2000;275:36703-36707. [PubMed: 10980195]

66. Pahan K, Jana M, Liu X, Taylor BS, Wood C, Fischer SM. Gemfibrozil, a lipid-lowering drug, inhibits the induction of nitric-oxide synthase in human astrocytes. J Biol Chem 2002;277:45984-45991. [PubMed: 12244038]

67. Marx N, Kehrle B, Kohlhammer BK, Grub M, Koenig W, Hombach V, et al. PPAR activators as antiinflammatory mediators in human T lymphocytes: implications for atherosclerosis and transplantation-associated arteriosclerosis. Circ Res 2002;90:703-710. [PubMed: 11934839]

68. Cunard R, DiCampli D, Archer DC, Stevenson JL, Ricote M, Glass CK, et al. WY14,643, a PPAR alpha ligand, has profound effects on immune responses in vivo. J Immunol 2002;169:6806-6812. [PubMed: 12471112]

69. Cunard R, Ricote M, DiCampli D, Archer DC, Kahn DA, Glass CK, et al. Regulation of cytokine expression by ligands of peroxisome proliferator activated receptors. J Immunol 2002;168:27952802. [PubMed: 11884448] 
70. Lovett-Racke AE, Hussain RZ, Northrop S, Choy J, Rocchini A, Matthes L, et al. Peroxisome proliferator-activated receptor alpha agonists as therapy for autoimmune disease. J Immunol 2004;172:5790-5798. [PubMed: 15100326]

71. Jones DC, Ding X, Zhang TY, Daynes RA. Peroxisome proliferator-activated receptor alpha negatively regulates $\mathrm{T}$-bet transcription through suppression of $\mathrm{p} 38$ mitogen-activated protein kinase activation. J Immunol 2003;171:196-203. [PubMed: 12816998]

72. Arnaud C, Veillard NR, Mach F. Cholesterol-independent effects of statins in inflammation, immunomodulation and atherosclerosis. Curr Drug Targets Cardiovasc Haematol Disord 2005;5:127-134. [PubMed: 15853754]

73. Elrod JW, Lefer DJ. The effects of statins on endothelium, inflammation and cardioprotection. Drug News Perspect 2005;18:229-236. [PubMed: 16034478]

74. Rosenson RS, Koenig W. Utility of inflammatory markers in the management of coronary artery disease. Am J Cardiol 2003;92:10i-18i.

75. Schillinger M, Exner M, Mlekusch W, Amighi J, Sabeti S, Muellner M, et al. Statin therapy improves cardiovascular outcome of patients with peripheral artery disease. Eur Heart J 2004;25:742-748. [PubMed: 15120884]

76. Graaf MR, Richel DJ, van Noorden CJ, Guchelaar HJ. Effects of statins and farnesyltransferase inhibitors on the development and progression of cancer. Cancer Treat Rev 2004;30:609-641. [PubMed: 15531395]

77. Wong WW, Dimitroulakos J, Minden MD, Penn LZ. HMG-CoA reductase inhibitors and the malignant cell: the statin family of drugs as triggers of tumor-specific apoptosis. Leukemia 2002;16:508-519. [PubMed: 11960327]

78. Alonso DF, Farina HG, Skilton G, Gabri MR, De Lorenzo MS, Gomez DE. Reduction of mouse mammary tumor formation and metastasis by lovastatin, an inhibitor of the mevalonate pathway of cholesterol synthesis. Breast Cancer Res Treat 1998;50:83-93. [PubMed: 9802623]

79. Matar P, Rozados VR, Roggero EA, Bonfil RD, Scharovsky OG. Inhibitory effect of lovastatin on spontaneous metastases derived from a rat lymphoma. Clin Exp Metastasis 1999;17:19-25. [PubMed: 10390143]

80. Downs JR, Clearfield M, Weis S, Whitney E, Shapiro DR, Beere PA, et al. Primary prevention of acute coronary events with lovastatin in men and women with average cholesterol levels: results of AFCAPS/TexCAPS. Air Force/Texas Coronary Atherosclerosis Prevention Study. JAMA 1998;279:1615-1622. [PubMed: 9613910]

81. Jakobisiak M, Golab J. Potential antitumor effects of statins. Int J Oncol 2003;23:1055-1069. [PubMed: 12963986]

82. Kim WS, Kim MM, Choi HJ, Yoon SS, Lee MH, Park K, et al. Phase II study of high-dose lovastatin in patients with advanced gastric adenocarcinoma. Invest New Drugs 2001;19:81-83. [PubMed: 11291836]

83. Larner J, Jane J, Laws E, Packer R, Myers C, Shaffrey M. A phase I-II trial of lovastatin for anaplastic astrocytoma and glioblastoma multiforme. Am J Clin Oncol 1998;21:579-583. [PubMed: 9856659]

84. Shepherd J, Blauw GJ, Murphy MB, Bollen EL, Buckley BM, Cobbe SM, et al. Pravastatin in elderly individuals at risk of vascular disease (PROSPER): a randomised controlled trial. Lancet 2002;360:1623-1630. [PubMed: 12457784]

85 . Tuomilehto J. Reducing coronary heart disease associated with type 2 diabetes: lifestyle intervention and treatment of dyslipidaemia. Diabetes Res Clin Pract 2003;61:S27-S34. [PubMed: 12880692]

86. Irons BK, Kroon LA. Lipid management with statins in type 2 diabetes mellitus. Ann Pharmacother 2005;39:1714-1718. [PubMed: 16118264]

87. Scuffham PA, Chaplin SA. A cost-effectiveness analysis of fluvastatin in patients with diabetes after successful percutaneous coronary intervention. Clin Ther 2005;27:1467-1477. [PubMed: 16291420]

88. Tsubouchi H, Inoguchi T, Sonta T, Sato N, Sekiguchi N, Kobayashi K, et al. Statin attenuates high glucose-induced and diabetes-induced oxidative stress in vitro and in vivo evaluated by electron spin resonance measurement. Free Radic Biol Med 2005;39:444-452. [PubMed: 16043016]

89. Ii M, Nishimura H, Kusano KF, Qin G, Yoon YS, Wecker A, et al. Neuronal nitric oxide synthase mediates statin-induced restoration of vasa nervorum and reversal of diabetic neuropathy. Circulation 2005;112:93-102. [PubMed: 15983249] 
90. Ohnaka K, Shimoda S, Nawata H, Shimokawa H, Kaibuchi K, Iwamoto Y, et al. Pitavastatin enhanced BMP-2 and osteocalcin expression by inhibition of Rho-associated kinase in human osteoblasts. Biochem Biophys Res Commun 2001;287:337-342. [PubMed: 11554731]

91. Ershler WB, Sun WH, Binkley N. The role of interleukin-6 in certain age-related diseases. Drugs Aging 1994;5:358-365. [PubMed: 7833589]

92. Chan KA, Andrade SE, Boles M, Buist DS, Chase GA, Donahue JG, et al. Inhibitors of hydroxymethylglutaryl-coenzyme A reductase and risk of fracture among older women. Lancet 2000;355:2185-2188. [PubMed: 10881890]

93. LaCroix AZ, Cauley JA, Pettinger M, Hsia J, Bauer DC, McGowan J, et al. Statin use, clinical fracture, and bone density in postmenopausal women: results from the Women's Health Initiative Observational Study. Ann Intern Med 2003;139:97-104. [PubMed: 12859159]

94. Sparks DL, Hunsaker JC 3rd, Scheff SW, Kryscio RJ, Henson JL, Markesbery WR. Cortical senile plaques in coronary artery disease, aging and Alzheimer's disease. Neurobiol Aging 1990;11:601607. [PubMed: 1704106]

95. Notkola IL, Sulkava R, Pekkanen J, Erkinjuntti T, Ehnholm C, Kivinen P, et al. Serum total cholesterol, apolipoprotein E epsilon4 allele, and Alzheimer's disease. Neuroepidemiology 1998;17:14-20. [PubMed: 9549720]

96. Sparks DL, Scheff SW, Hunsaker JC III, Liu H, Landers T, Gross DR. Induction of Alzheimer-like $\beta$-amyloid immunoreactivity in the brains of rabbits with dietary cholesterol. Exp Neurol 1994;126:88-94. [PubMed: 8157129]

97. Jick H, Zornberg GL, Jick SS, Seshadri S, Drachman DA. Statins and the risk of dementia. Lancet 2000;356:1627-1631. [PubMed: 11089820]

98. Wolozin B, Kellman W, Ruosseau P, Celesia G, Siegel G. Decreased prevalence of Alzheimer disease associated with 3-hydroxy-3-methyglutaryl coenzyme A reductase inhibitors. Arch Neurol 2000;57:1439-1431. [PubMed: 11030795]

99. Sparks DL, Sabbagh MN, Connor DJ, Lopez J, Launer LJ, Browne P, et al. Atorvastatin for the treatment of mild to moderate Alzheimer disease: preliminary results. Arch Neurol 2005;62:753757. [PubMed: 15883262]

100. Stuve O, Youssef S, Steinman L, Zamvil SS. Statins as potential therapeutic agents in neuroinflammatory disorders. Curr Opin Neurol 2003;16:393-401. [PubMed: 12858078]

101. Greenwood J, Walters CE, Pryce G, Kanuga N, Beraud E, Baker D, et al. Lovastatin inhibits brain endothelial cell Rho-mediated lymphocyte migration and attenuates experimental autoimmune encephalomyelitis. FASEB J 2003;17:905-907. [PubMed: 12626426]

102. Stanislaus R, Pahan K, Singh AK, Singh I. Amelioration of experimental allergic encephalomyelitis in Lewis rats by lovastatin. Neurosci Lett 1999;269:71-74. [PubMed: 10430507]

103. Vollmer T, Key L, Durkalski V, Tyor W, Corboy J, Markovic-Plese S, et al. Oral simvastatin treatment in relapsing-remitting multiple sclerosis. Lancet 2004;363:1607-1608. [PubMed: 15145635]

104. Bretillon L, Siden A, Wahlund LO, Lutjohann D, Minthon L, Crisby M, et al. Plasma levels of 24Shydroxycholesterol in patients with neurological diseases. Neurosci Lett 2000;293:87-90.

[PubMed: 11027840]

105. Teunissen CE, Dijkstra CD, Polman CH, Hoogervorst EL, von Bergmann K, Lutjohann D. Decreased levels of the brain specific 24S-hydroxycholesterol and cholesterol precursors in serum of multiple sclerosis patients. Neurosci Lett 2003;347:159-162. [PubMed: 12875910]

106. Young-Xu Y, Chan KA, Liao JK, Ravid S, Blatt CM. Long-term statin use and psychological wellbeing. J Am Coll Cardiol 2003;42:690-697. [PubMed: 12932603]

107. Yang CC, Jick SS, Jick H. Lipid-lowering drugs and the risk of depression and suicidal behavior. Arch Intern Med 2003;163:1926-1932. [PubMed: 12963565]

108. Fazio S, Linton MF. The role of fibrates in managing hyperlipidemia: mechanisms of action and clinical efficacy. Curr Atheroscler Rep 2004;6:148-157. [PubMed: 15023300]

109. Duez H, Chao YS, Hernandez M, Torpier G, Poulain P, Mundt S, et al. Reduction of atherosclerosis by the peroxisome proliferator-activated receptor alpha agonist fenofibrate in mice. J Biol Chem 2002;277:48051-48057. [PubMed: 12377786] 
110. Israelian-Konaraki Z, Reaven PD. Peroxisome proliferator-activated receptor-alpha and atherosclerosis: from basic mechanisms to clinical implications. Cardiol Rev 2005;13:240-246. [PubMed: 16106185]

111. Winkler K, Weltzien P, Friedrich I, Schmitz H, Nickell HH, Hauck P, et al. Qualitative effect of fenofibrate and quantitative effect of atorvastatin on LDL profile in combined hyperlipidemia with dense LDL. Exp Clin Endocrinol Diabetes 2004;112:241-247. [PubMed: 15146369]

112. Ikeda U. Inflammation and coronary artery disease. Curr Vasc Pharmacol 2003;1:65-70. [PubMed: 15320854]

113. Biswas P, Delfanti F, Bernasconi S, Mengozzi M, Cota M, Polentarutti N, et al. Interleukin-6 induces monocyte chemotactic protein-1 in peripheral blood mononuclear cells and in the U937 cell line. Blood 1998;91:258-265. [PubMed: 9414293]

114. Chapman MJ. Beyond the statins: new therapeutic perspectives in cardiovascular disease prevention. Cardiovasc Drugs Ther 2005;19:135-139. [PubMed: 16025232]

115. Koh KK, Quon MJ, Han SH, Chung WJ, Ahn JY, Seo YH, et al. Additive beneficial effects of fenofibrate combined with atorvastatin in the treatment of combined hyperlipidemia. J Am Coll Cardiol 2005;45:1649-1653. [PubMed: 15893182]

116. De Angelis G. The influence of statin characteristics on their safety and tolerability. Int J Clin Pract 2004;58:945-955. [PubMed: 15587774]

117. Wang JS, Neuvonen M, Wen X, Backman JT, Neuvonen PJ. Gemfibrozil inhibits CYP2C8-mediated cerivastatin metabolism in human liver microsomes. Drug Metab Dispos 2002;30:1352-1356. [PubMed: 12433802]

118. Ji H, Outterbridge LV, Friedman MI. Phenotype-based treatment of dietary obesity: differential effects of fenofibrate in obesity-prone and obesity-resistant rats. Metabolism 2005;54:421-429. [PubMed: 15798946]

119. Zhang F, Chen Y, Heiman M, Dimarchi R. Leptin: structure, function and biology. Vitam Horm 2005;71:345-372. [PubMed: 16112274]

120. Couce ME, Green D, Brunetto A, Achim C, Lloyd RV, Burguera B. Limited brain access for leptin in obesity. Pituitary 2001;4:101-110. [PubMed: 11824502]

121. Banks WA, Coon AB, Robinson SM, Moinuddin A, Shultz JM, Nakaoke R, et al. Triglycerides induce leptin resistance at the blood-brain barrier. Diabetes 2004;53:1253-1260. [PubMed: 15111494]

122. Toruner F, Akbay E, Cakir N, Sancak B, Elbeg S, Taneri F, et al. Effects of PPARgamma and PPARalpha agonists on serum leptin levels in diet-induced obese rats. Horm Metab Res 2004;36:226-230. [PubMed: 15114521]

123. Diabetes Atherosclerosis Intervention Study Investigators. Effect of fenofibrate on progression of coronary-artery disease in type 2 diabetes: the Diabetes Atherosclerosis Intervention Study, a randomized study. Lancet 2001;357:905-910. [PubMed: 11289345]

124. Elkeles RS, Diamond JR, Poulter C, Dhanjil S, Mahmood S, Richmond W, et al. Cardiovascular outcomes in type 2 diabetes: a double-blind placebo-controlled study of bezafibrate: the St. Mary's, Ealing, Northwick Park Diabetes Cardiovascular Disease Prevention (SENDCAP) Study. Diabetes Care 1998;21:641-648. [PubMed: 9571357]

125. Shulman GI. Cellular mechanisms of insulin resistance. J Clin Invest 2000;106:171-176. [PubMed: 10903330]

126. Sedova L, Seda O, Krenova D, Kren V, Kazdova L. Isotretinoin and fenofibrate induce adiposity with distinct effect on metabolic profile in a rat model of the insulin resistance syndrome. Int J Obes Relat Metab Disord 2004;28:719-725. [PubMed: 15007394]

127. Pineda Torra I, Gervois P, Staels B. Peroxisome proliferator-activated receptor alpha in metabolic disease, inflammation, atherosclerosis and aging. Curr Opin Lipidol 1999;10:151-159. [PubMed: 10327283]

128. Schernthaner GH, Schernthaner G. Insulin resistance and inflammation in the early phase of type 2 diabetes: potential for therapeutic intervention. Scand J Clin Lab Invest 2005;240(Suppl):30-40.

129. Gonzalez FJ, Peters JM, Cattley RC. Mechanism of action of the nongenotoxic peroxisome proliferators: role of the peroxisome proliferator-activator receptor alpha. J Natl Cancer Inst 1998;90:1702-1709. [PubMed: 9827524] 
130. Braun L, Mile V, Schaff Z, Csala M, Kardon T, Mandl J, et al. Induction and peroxisomal appearance of gulonolactone oxidase upon clofibrate treatment in mouse liver. FEBS Lett 1999;458:359-362. [PubMed: 10570940]

131. Alsheikh-Ali AA, Kuvin JT, Karas RH. Risk of adverse events with fibrates. Am J Cardiol 2004;94:935-938. [PubMed: 15464682]

132. Ledesma MD, Dotti CG. The conflicting role of brain cholesterol in Alzheimer's disease: lessons from the brain plasminogen system. Biochem Soc Symp 2005;72:129-138. [PubMed: 15649137] 


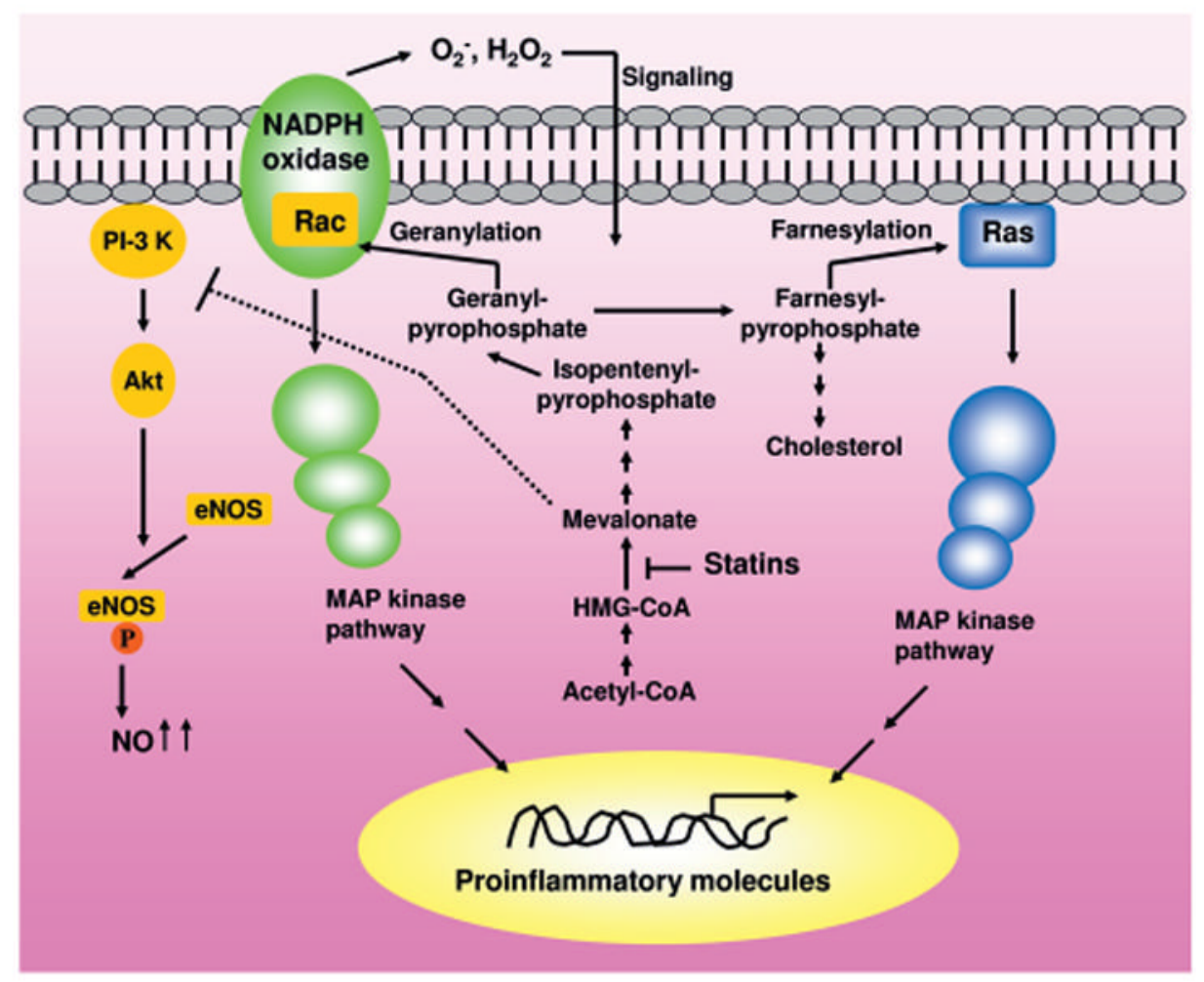

Figure 1.

Schematic diagram depicting the various functions of statins. Statins suppress HMG-CoA reductase and thereby inhibit geranylation of Rac and farnesylation of Ras. Because both Rac and Ras are coupled to the transcription of proinflammatory molecules via MAP kinase pathways, statins reduce the expression of proinflammatory molecules. By suppressing geranylation of Rac, statins also attenuate NADPH oxidase-mediated production of reactive oxygen species (ROS). Phosphatidylinositol-3 (PI-3) kinase activates Akt, the kinase that has been shown to phosphorylate and stimulate endothelial nitric oxide synthase (eNOS).

Mevalonate is capable of inhibiting PI-3 kinase, therefore, by reducing the concentration of mevalonate, statins up-regulate eNOS-derived production of NO resulting in vasorelaxation. 


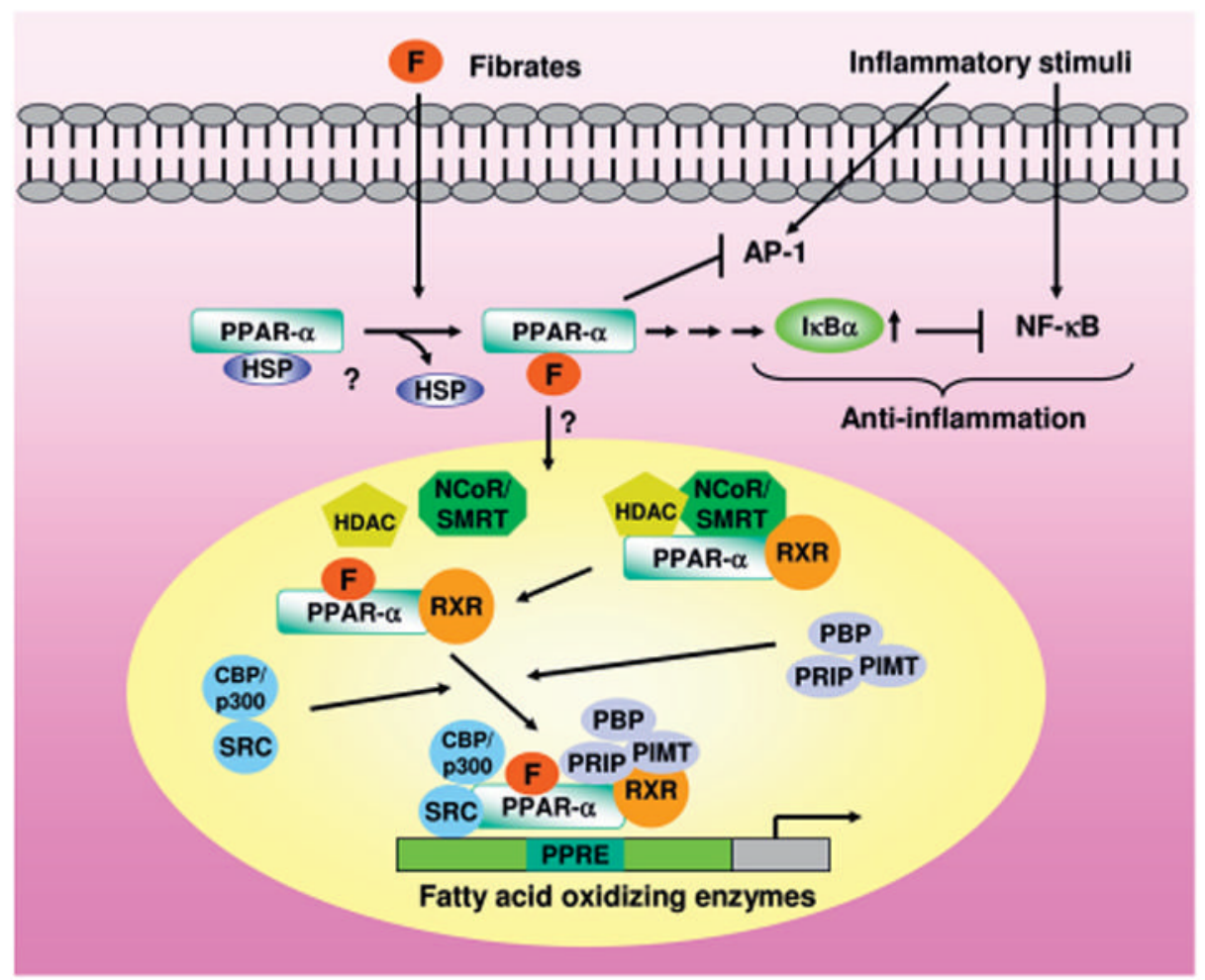

Figure 2.

Lipid-lowering and anti-inflammatory functions of fibrate drugs. PPAR- $\alpha$ in the cytoplasm has been shown to bind heat-shock protein (HSP). However, the role of HSP is at present unclear. As has been shown in case of other nuclear hormone receptors, fibrates (F) may replace HSP. It has also not been demonstrated if ligand-bound PPAR- $\alpha$ enters into the nucleus. Within the nucleus, PPAR- $\alpha$ and RXR complex is bound to repressors, such as nuclear receptor corepressor (NCoR), silencing mediator for retinoid and thyroid hormone receptor (SMRT) and histone deacetylase (HDAC). In the presence of ligand, NCoR, SMRT and HDAC are released from the complex followed by the recruitment of histone acetyltransferase (CBP/p300), steroid receptor co-activator (SRC), PPAR-binding protein (PBP), PPAR-interacting protein (PRIP), and PRIP-interacting protein with methyltransferase domain (PIMT). Subsequently, the whole active complex binds to peroxisome proliferator responsive element (PPRE) present in the promoter of peroxisomal fatty acid $\beta$-oxidizing enzymes. On the other hand, fibrates also inhibit the activation of AP- 1 and NF- $\kappa$ B via PPAR $-\alpha$. Although PPAR- $\alpha$ has been suggested to be involved in the up-regulation of $\mathrm{I} \kappa \mathrm{B} \alpha$, underlying mechanisms are unknown. 